\title{
Changes in stroke distance in response to haemorrhage in a swine model
}

\author{
M J Clancy, J Alderman, N Cavallero, K J W Taylor
}

\begin{abstract}
Objective-To determine, using an animal model of blood loss, (1) if stroke distance, derived non-invasively from the time integral of the maximum velocity of red cells in the aorta, changed to a greater extent than heart rate and mean arterial pressure (MAP), which are recognised to be unreliable indicators of blood loss; (2) if changes in stroke distance reflected changes in stroke volume derived from thermodilution cardiac output measurements.

Methods-Eight anaesthetised swine had baseline measurements of heart rate, MAP, stroke volume, and stroke distance and were then exsanguinated at a rate of 1 $\mathrm{ml} / \mathrm{kg} / \mathrm{min}$. Percentage changes from baseline of heart rate, MAP, stroke volume, and stroke distance were compared after 10, 20, and $30 \mathrm{ml} / \mathrm{kg}$ blood loss. The animal's blood was then reinfused at the rate of $2 \mathrm{ml} / \mathrm{kg} / \mathrm{min}$ for $15 \mathrm{~min}$, followed by normal saline $1 \mathrm{ml} / \mathrm{kg} / \mathrm{min}$. Percentage changes from baseline measurement of stroke volume and stroke distance over the whole experiment were evaluated by regression analysis.
\end{abstract}

Results-Heart rate, MAP, and stroke distance changed $+7.9 \%,-22.5 \%$, and $-18.1 \%$ respectively (from baseline values) after $10 \mathrm{ml} / \mathrm{kg}$ blood loss; $+23.2 \%,-44.0 \%$, and $-47.4 \%$ after $20 \mathrm{ml} / \mathrm{kg}$ blood loss; and $+55.7 \%,-62.0 \%$, and $-69.8 \%$ after $30 \mathrm{ml} / \mathrm{kg}$ blood loss. Regression analysis of percentage changes in stroke volume and stroke distance from their baseline values at experimental time zero is stroke volume = $1.014 \times$ stroke distance $-2.156, r=0.92, \mathrm{n}=$ $54, P<0.0001$.

Accident and Emergency Department, Bristol Royal Infirmary, Bristol BS2 8HW, United Kingdom M J Clancy

Ultrasound section, Department of Radiology, Yale University School of Medicine, New Haven, Connecticut, USA

J Alderman

N Cavallero

K J W Taylor

Correspondence to: Mr M J Clancy.

Accepted for publication 19 February 1996 those first treating such patients may be part of the problem, but the limitations of the traditional signs of blood loss - hypotension

Failure to treat blood loss causes death, and the failure to recognise blood loss is a factor and an increase in heart rate-may also be important. ${ }^{34}$ Thus previously healthy individuals may lose up to $30 \%$ of their blood volume before there is any significant hypotension. ${ }^{5}$ Several investigators ${ }^{6} 7$ have noted that there is no obvious relation between pulse rate and blood volume. Urine output is relatively easy to measure but requires timed collection, which inevitably lags behind events and is not reduced in a uniform manner during blood loss. ${ }^{8}$ Cardiac output is usually measured using a thermodilution catheter but is invasive, potentially dangerous especially in shocked patients, provides only intermittent readings, and is inappropriate during the initial resuscitation of the patient.

Stroke volume quantitatively defines the beat to beat volumetric performance of the heart and is determined by preload, contractility, and afterload. During haemorrhage preload diminishes, with consequent reduction in stroke volume despite increased myocardial activity. Additionally, compensatory augmentation of afterload results in further stroke volume reduction. ${ }^{9}$ Thus stroke volume would appear a more fundamental measure of blood loss, not subject to compensatory changes to the same extent as cardiac output, blood pressure, and urine output. Several animal studies confirm that of the commonly measured variables stroke volume changes to the greatest extent during haemorrhage. ${ }^{10}{ }^{11}$ Ultrasound offers the possibility of noninvasive indirect measurement of stroke volume by the measurement of aortic blood velocity which, when intregrated over the ejection time, gives stroke distance (see below).

The ultrasound measurement of stroke volume relies on the Doppler effect and certain assumptions regarding flow within the aorta. By the use of the Doppler equation the velocity of the red cells within an ultrasound beam can be measured. If the blood ejected into the aorta (stroke volume) is considered to be a cylinder, then by knowing the mean velocity of the red cells and the ejection time, a distance (stroke distance) can be measured which, if multiplied by the cross sectional area of the aorta, produces a volume (equivalent to the stroke volume). However, the following assumptions must be made: (1) that the velocity profile of the blood is uniform across the aorta and that all red cells travel at the same speed, that is, that the mean velocity is simply equal to the maximum velocity near the centre of the aorta; (2) that the ultrasound beam is at a known or zero angle to the aortic flow; (3) that the cross sectional area can be accurately calculated, and remains unchanged during blood loss. 


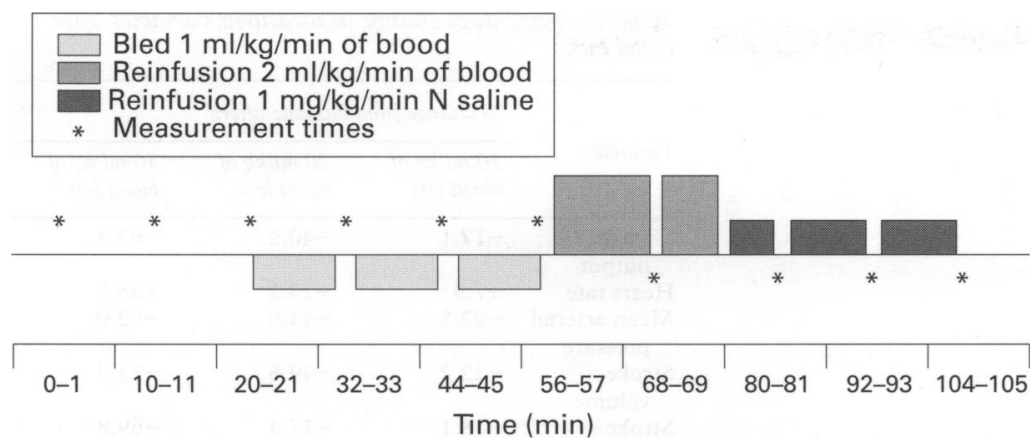

Figure 1 Schematic representation of experimental protocol.

Several workers have used the assumed velocity profile method to measure and monitor changes in cardiac output, with good correlation being reported with invasive cardiac output estimates. ${ }^{12}{ }^{13}$ However, each assumption introduces considerable error. ${ }^{14}$ The predominant requirement of any variable during immediate resuscitation from haemorrhagic shock is that its changing value reflects the rate of blood loss and the response to treatment, that is, that the change in a variable is of more value than its absolute value. It was proposed that changes in stroke distance would closely correlate with changes in stroke volume. This assumes that the errors introduced by assumptions 1-3 remain constant during haemorrhagic shock.

It was decided to compare changes from their baseline values of mean arterial pressure, heart rate, cardiac output (measured by thermodilution technique), stroke volume (thermodilution cardiac output/heart rate), and stroke distance during progressive blood loss in swine, and then to reinfuse the animal and to subject the changes in stroke volume and stroke distance over the whole experiment to a least squares regression analysis.

\section{Methods}

EOUIPMENT AND EXPERIMENTAL PROCEDURE

Eight female Yorkshire pigs (mean weight 28.9 $\mathrm{kg}$, range $25-31 \mathrm{~kg}$ ) were starved overnight but permitted water ad libitum. On the morning of the experiment they were sedated using ketamine $(30 \mathrm{mg} / \mathrm{kg}$ ) and 10 minutes later anaesthesia was induced using halothane through a nose cone. A tracheostomy was performed and a $7.5 \mathrm{~mm}$ tube inserted and secured. The following lines were inserted: a femoral arterial line ( $5 \mathrm{~F}$ polyethylene) for measurement of mean arterial pressure and heart rate, a left internal jugular line for bleeding and reinfusion (connected to a rotary pump), and a 7.5F Swan Ganz catheter (placement confirmed by typical pulmonary artery tracings and dampening of the pressure wave formed on balloon inflation) through the right jugular vein. All lines were flushed with heparinised saline and the animal was heparinised with 5000 units of intravenous heparin. A Foley catheter was inserted into the bladder via a suprapubic cystotomy. Cardiac output was calculated during expiration using an American Edwards cardiac output computer and the mean taken of the two closest values of four injectates of $5 \mathrm{ml}$ of normal saline at room temperature. In an attempt to reduce the effect of halothane, its concentration was reduced in $0.5 \%$ intervals (Fluorotec vaporiser) to the minimum required to prevent spontaneous movement by the animal and any response to skin pinch or pressure. Halothane was given with $50 \%$ nitrous oxide and $50 \%$ oxygen through a closed rebreathing circuit with the animal breathing spontaneously. The animal was immobilised in a cradle and blankets were used to reduce heat loss. (There was no attempt to maintain the animal's body temperature beyond this.)

The ultrasound anatomy of the pig is not well recognised and thus no assumptions regarding orientation of the aorta could be made. The heart was visualised using a 2.25 $\mathrm{MHz}$ sector scanner from the apical window. The aortic root and its orientation were identified and it was apparent that the aorta curved abruptly posteriorly and laterally. The aortic root was imaged to visualise the greatest length of proximal aorta so that the angle between the ultrasound beam and the aortic root was minimised. The sample volume $(5 \mathrm{~mm})$ was placed in the centre of the aorta at the level of the sinuses of Valsalva. Waveforms from the aortic root were recorded on a super VHS videotape immediately after the cardiac output injections for later analysis.

The aortic diameter at the level of the sinuses of Valsalva was measured at the onset of the $Q$ wave using $M$ mode, measuring from leading edge to leading edge at the beginning of the experiment and during the removal of $20-30 \mathrm{ml}$ of blood/kg (during experimental time 46-56 $\mathrm{min}$ ).

The experimental protocol (fig 1) started 160 min after the administration of ketamine and baseline readings (mean arterial pressure, heart rate, cardiac output, arterial blood gases, blood temperature, and aortic waveforms) were taken at the experimental time of 0,10 , and $20 \mathrm{~min}$. Each set of readings was taken over a $2 \mathrm{~min}$ period. At minute 22, bleeding was begun at a rate of $1 \mathrm{ml} / \mathrm{kg} / \mathrm{min}$ for $10 \mathrm{~min}$, with measurements made at minute 32 . This cycle was repeated on a further two occasions, with a total blood loss of $30 \mathrm{ml} / \mathrm{kg}$. The animal's blood was then reinfused at a rate of $2 \mathrm{ml} / \mathrm{kg} / \mathrm{min}$ for $15 \mathrm{~min}$ and the infusion was continued using normal saline $(1 \mathrm{ml} / \mathrm{kg} / \mathrm{min})$ for a further $30 \mathrm{~min}$. Measurements were again taken at $10 \mathrm{~min}$ intervals. At the end of the experiment the anaesthetised animals were killed with an intravenous bolus of potassium chloride $(25 \mathrm{mg} / \mathrm{kg})$.

The protocol was approved by the Yale animal care and use committee.

Stroke distance was calculated from 10 consecutive waveforms, which were played back on a Hewlett Packard HPsonos 1000. Each waveform was traced following the envelope of the maximum velocity to derive a time average of the maximum velocity, which was multiplied by the ejection time to give the stroke distance.

DATA ANALYSIS

Values for each of the variables are presented as the mean(SEM). To test if the changes over 


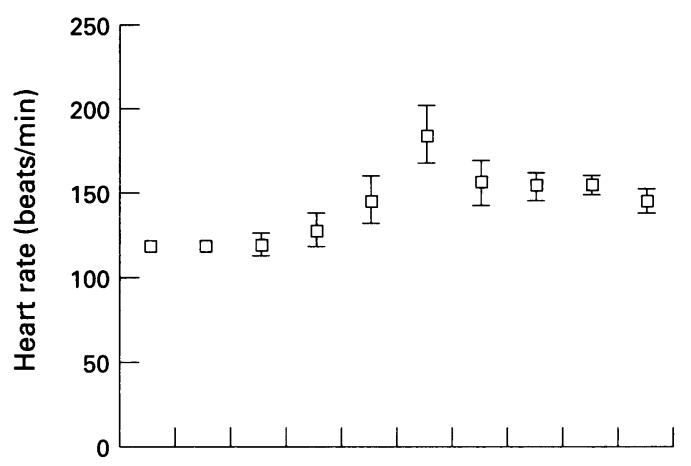

Table 1 Percentage change in measured variables after blood loss

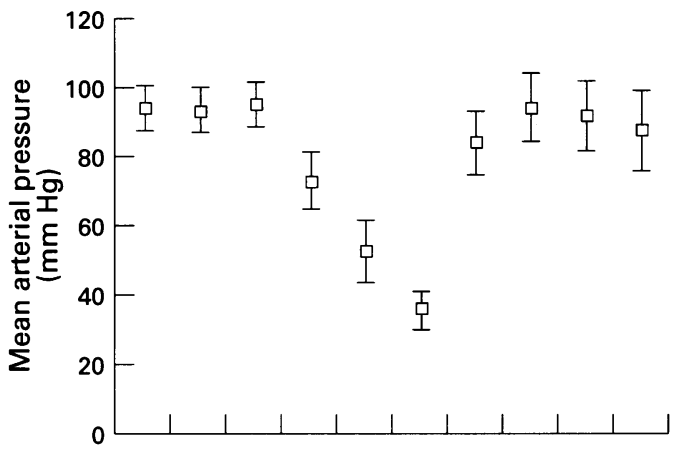

\begin{tabular}{llll}
\hline \multirow{4}{*}{ Variable } & \multicolumn{3}{l}{$\%$ change from baseline after: } \\
\cline { 2 - 4 } & $\begin{array}{l}\text { 10 ml/kg of } \\
\text { blood loss }\end{array}$ & $\begin{array}{l}\text { 20 ml/kg of } \\
\text { blood loss }\end{array}$ & $\begin{array}{l}30 \mathrm{ml} / \mathrm{kg} \text { of } \\
\text { blood loss }\end{array}$ \\
\hline $\begin{array}{c}\text { Cardiac } \\
\text { output }\end{array}$ & -17.1 & -40.2 & -63.3 \\
$\begin{array}{c}\text { Heart rate } \\
\text { Mean arterial } \\
\text { pressure }\end{array}$ & +7.9 & +23.2 & +55.7 \\
$\begin{array}{c}\text { Stroke } \\
\text { volume }\end{array}$ & -22.2 & -44.0 & -62.0 \\
$\begin{array}{c}\text { Stroke } \\
\text { distance }\end{array}$ & -18.1 & -49.8 & -75.0 \\
\hline
\end{tabular}

time are significant $(P<0.05)$, an analysis of variance for repeated measures were performed using Systat 5 (Systat Inc). This divides the variance into two: the part that occurs between animals at the same time, and that which occurs across the time of the study. The significance values quoted are for the change across time but do not infer that the differences are between any particular timed group. The use of this method avoids the problem of repeated $t$ tests, namely that there is a risk of a "significant result" by chance alone

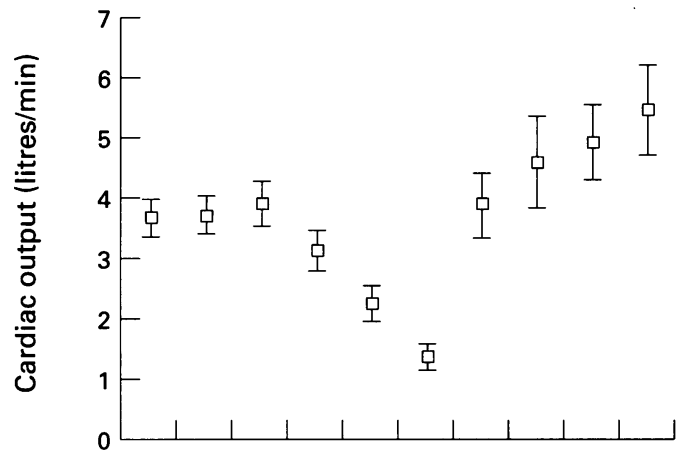
(that is, type I error). The percentage change of each variable from its baseline value (average of the means of the baseline values at time 0,10 , and 20 ) and after $10,20,30 \mathrm{ml} / \mathrm{kg}$ blood loss are compared. The percentage change in stroke volume and stroke distance (from their baseline values at experimental time zero) over the whole experiment are subjected to a least squares regression analysis to derive a regression coefficient $r$. The aortic diameter measurements measured at time zero and during the period of $20-30 \mathrm{ml} / \mathrm{kg}$ blood loss are subjected to a paired Students $t$ test $(P<0.05$ taken as significant).

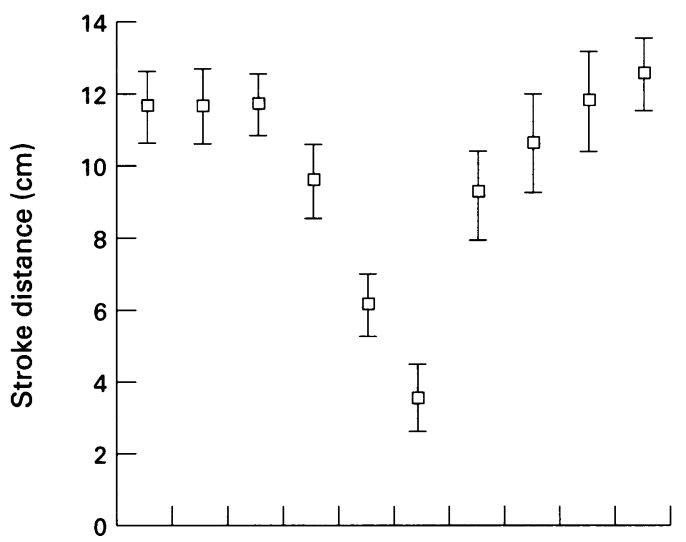

\section{Results}

The changes during blood loss in mean arterial pressure, heart rate, cardiac output, stroke volume, and stroke distance are shown in fig 2 . All show significant changes $(P<0.05)$. The percentage change of each variable after 10 , 20 , and $30 \mathrm{ml} / \mathrm{kg}$ blood loss are shown in table 1. The corresponding changes in stroke volume and stroke distance are plotted in fig 3 . The results of the least squares regression analysis are shown in table 2 . The aortic diameter measurements at time zero and at experimental time 49 to $54 \mathrm{~min}$ are shown in table 3 and there was no significant difference. Two animals died after 10 and $19 \mathrm{~min}$ of reinfusion. The central venous blood temperature

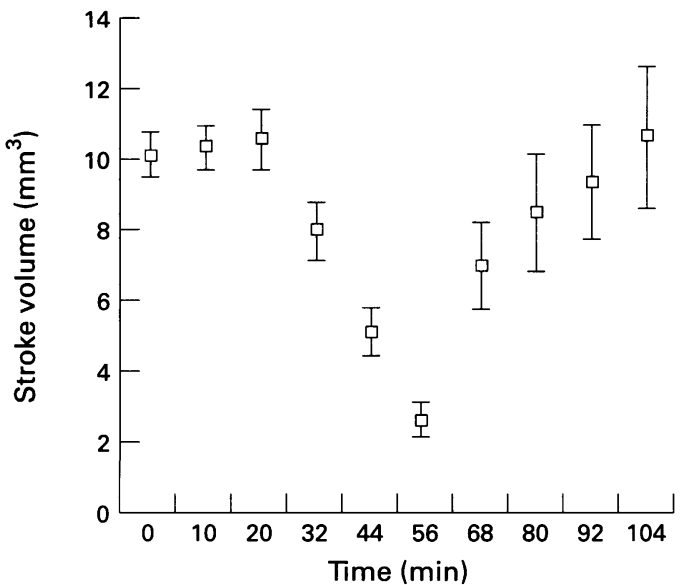
at the commencement of the experiment was 37.6 (standard error 0.21 ) and at the end of the experiment was 36.8 (standard error 0.38).

\section{Discussion}

Swine were chosen because the functional characteristics of their cardiovascular system more closely resemble those of man than those

Table 2 Least squares regression analysis of stroke volume $(S V) v$ stroke distance (SD)

For all observations $(n=54)$

$\mathrm{SV}=1.014 \mathrm{SD}-2.156 \quad r=0.92 \quad \mathrm{P}=<0.0001$




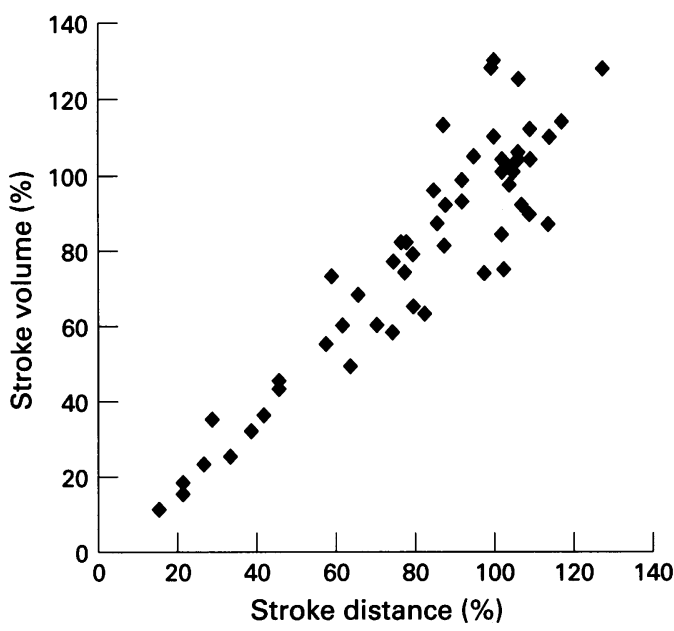

Figure 3 Percentage changes in stroke volume and stroke distance over the whole experiment from their baseline values at time zero.

Table 3 Aortic diameter measurements: change with blood loss

\begin{tabular}{lll}
\hline & Time 0 & Time 49-54 \\
\hline Aortic diameter $(\mathrm{cm})$ & 2.22 & 2.12 \\
& 2.12 & 2.15 \\
& 2.09 & 1.95 \\
& 2.26 & 2.06 \\
\hline
\end{tabular}

$(P=0.126)$.

of the $\operatorname{dog}^{15}$ and this is reflected by the popularity of the pig in shock research. The size of the animal was important to enable ultrasonic examination of the heart and for the ease of monitoring. Although it is recognised that conscious animals represent the best model, this requires considerable expertise and cost. Therefore, an anaesthetised model was used, with attempts made to minimise the effect of the anaesthetic agents. Thus the experiment was not started until 160 minutes after the administration of ketamine. Previous investigators have noted that with a dose of 20 $\mathrm{mg} / \mathrm{kg}$ there is resolution of the effects of this agent after about 90 minutes. ${ }^{16}$ Halothane has a marked negative inotropic effect, with depression of cardiac output and stroke volume $^{17} 18$ and this will depress the pig's Starling curves. However, halothane was used because it provided a stable, rapidly controllable depth of anaesthesia, and attempts were made to minimise its effect by using the minimum required to stop the animal moving in response to pinch or from the pressure of an ultrasound probe, and by the addition of $50 \%$ nitrous oxide.

The controlled continuous haemorrhage model ${ }^{19}$ chosen here represents a compromise between the ideal shock model, that is, that of uncontrolled haemorrhage which provides little time for monitoring with changes occurring very rapidly, and that of the fixed volume withdrawal model and fixed pressure model which are of limited relevance in shock research. ${ }^{20}$

In conscious swine subjected to haemorrhage there is a more sustained maintenance of mean arterial blood pressure ${ }^{21}$ and reduction in cardiac output to a lesser extent. ${ }^{22}$ The early fall in blood pressure and large drop in cardiac output presumably reflects the negative ino- tropic effect of halothane and its depressant effect on a normal response to haemorrhage. Halothane has been noted to depress the baroreceptor reflex in human ${ }^{23}$ and to depress the responsiveness of vascular smooth muscle. ${ }^{24}$ Stroke volume, however, was the variable which changed to the greatest extent. Overall there was a good correlation between changes in stroke volume and stroke distance, but this was not the case after the first $10 \mathrm{ml} / \mathrm{kg}$ blood loss. The poorer correlation between the two variables at higher stroke volume and distance is evident (fig 3). This may be due to a breakdown in any of the original three assumptions. However, the cross sectional area did not change significantly in the four animals in which it was measured, but this small number limits the power of the $t$ test. Other investigators $^{25}{ }^{26}$ have confirmed a reduction in cross sectional area with reduction in blood pressure in the descending aorta; however, because the aortic diameter was measured at the level of the sinuses of Valsalva immediately adjacent to the valve, it may not be subjected to such changes because of the rigidity of the valve. The stroke distance changes less after $10 \mathrm{ml} / \mathrm{kg}$ blood loss than stroke volume, and this may be because the ratio of the maximum to the mean velocity has decreased, that is, reductions in mean velocity are not accurately reflected by changes in the time averaged maximum velocity. The closer relation of stroke volume to stroke distance after volume losses of 20 and $30 \mathrm{ml} / \mathrm{kg}$ presumably reflects the fact that the change in maximum velocity is greater than any further changes in the relation of the maximum to the mean velocity. Interestingly the two animals that died did so during the reinfusion phase and not at the time of maximum blood loss. This suggests that there was limited capacity of the heart to handle the infused volume of fluid and in this case the limit may have been set not only by the anaesthetic agents but also by the blood loss.

In conclusion, this model shows that stroke volume was the variable that had the greatest percentage change from baseline during haemorrhage and there was a close correlation with changes in stroke volume and stroke distance measured by ultrasound. However, stroke distance underestimated the early changes in stroke volume, presumably because of a breakdown in the relation of the maximum velocity to the mean velocity. This may be important in those machines that measure maximum frequency, from which the mean is directly computed. Stoke distance measurement, however, offers a real opportunity to improve on the conventionally measured variables of heart rate and blood pressure during the initial assessment and treatment of hypovolaemic shock.

This work was supported by a grant from the Smith \& Nephew Foundation to MC. We would like to acknowledge the statistical help provided by Dr Chris Day, Academic Department of Anaesthesia, Bristol Royal Infirmary.

1 Anderson ID, Woodford M, DeDombal T, Irving M. Retrospective study of 1000 deaths in England and Wales. $B M$ 1988;296:1305-8.

2 Trunkey D. Trauma. Sci Am 1983;249:28-35. 
3 Little RA, Gorman D, Allgower M. Shock index revisited. In: Vincent JL, ed. Update in intensive care and emergency medicine, vol 10. Berlin: Springer, 1990:505-12.

4 Wo CC, Shoemaker WC, Appel PL, Bishop MH, Kram HB, Harding E. Unreliability of blood pressure and heart rate to evaluate cardiac output in emergency resuscitation and evaluate cardiac output in emergency resuscitat
critical illnesses. Crit Care Med 1993;21:218-23.

5 Peitzman A. Principles of circulatory support and the treatment of haemorrhagic shock. In: Synder JV, Pinsky MR eds. Oxygen transport in the critically ill. Chicago: Year Book Publishers, 1981:401.

6 Emerson CP, Ebert RV. A study of shock in battle casualties. Ann Surg 1945;122:745.

7 Keith NM. Blood volume changes in wound shock and primary haemorrhage. Special Report Series, Medical Research Committee, 1919;25:213-34.

8 Lucas CE. Renal considerations in the injured patient. Surg Clin North Am 1982;62:133-48.

9 Bernstein DP. Oxygen transport and utilization in trauma. In: Capon LM, Miller SM, Turndorf $\mathrm{H}$, eds. Trauma, anaesthetia and intensive care Philadelphia: Lippincott, 1991:115.

10 Maningas PA. Resuscitation with $7.5 \% \mathrm{NaCl}$ in $6 \%$ dextran-70 during hemorrhage shock in swine: effects on organ blood flow. Crit Care Med 1987;15:1121-6.

11 Schwart S, Franz RA, Shoemaker WC. Sequential hemodynamic and oxygen transport responses in hypovolaemia namic and oxygen transport responses in hypovolaem

12 Huntsman LL, Stewart DK, Barnes SR, Franklin SB, Colocousis JS, Hessel EA. Non-invasive Doppler determination of cardiac output in man: clinical validation. Circulation 1983;67:593-602.

13 Colocousis JS, Huntsman LL, Curreri PW. Estimation of stroke volume changes by ultrasonic Doppler. Circulation 1977;56:914-7.

14 Bernstein DP. Non-invasive cardiac output measurement. In: Shoemaker WC, ed. Textbook of critical care. Philadelphia: WB Saunders, 1992:159-85.

15 Terris JM. Swine as a model in renal physiology and nephrology: an overview. In: Tumbleson ME, ed. Swine in biomedical research. New York: Plenum Press, 1986:167389.

16 Thurmon JC, Nelson JC, Christie GJ. Ketamine anesthesia in swine. $\mathcal{F}$ Am Vet Med Assoc 1972;160:1325-30.

17 Tranquilli WJ, Manohar M, Parks CM, Thurmon JC Theodorakis MC, Benson GJ. Systemic and regional blood flow distribution in unanaesthetised swine and swine anaesthetised with halothane and nitrous oxide, halothane or enfluxane. Anaesthesiology 1982;56:369-79.

18 Merin RG, Verdouw PD, de Jong GW. Dose-dependent depression of cardiac function and metabolism by halothane in swine (Sus scrofa). Anaesthesiology 1977;46:417-23.

19 Syverud SA, Dronen SC, Chudnofsky CR, Van-Ligten PF. A continuous haemorrhagic model of fatal haemorrhagic shock in swine. Resuscitation 1989;17:287-95.

20 Bellamy RF, Maningas P, Wenger BA. (1986) Current shock models and clinical correlations. Ann Emerg Med 1986;15: 1392-5.

21 Sondeen JL, Gonzaledo GA, Loveday JA, Deshon GE, Clifford CB, Hunt MM, et al. Renal responses to graded hemorrhage in conscious pig. Am F Physiol 1990;259:R1 19-25.

22 Shackford SR, Norton CH, Todd MM. Renal, cerebral and pulmonary effects of hypertonic resuscitation in a porcine model of haemorrhagic shock. Surgery 1988;104:553-60.

23 Duke PC, Fownes D, Wade JG. Halothane depresses baro reflex control of heart rate in man. Anesthesiology 1977;46: 184.

24 Spiss CK, Smith CM, Tsujimoto G, Hoffman BB, Maze M. Prolonged hyporesponsiveness of vascular smooth muscle contraction after halothane anesthesia in rabbits. Anesth Analg 1985;64:1-6.

25 List W, Gravenstein N, Banner T, Caton D, Davis RF. Interaction in sheep between mean arterial pressure and cross-sectional area of the descending aorta: implications for esophageal Doppler monitoring [abstr]. Anaesthesiology 1987;67:A178.

26 Kamal GD, Davies GG, Starr J. Misleading esophageal Doppler cardiac output during early haemorrhage in pigs [abstr]. Anaesth Analg 1988;67:S106. 